\title{
Relationship between particulate matter and childhood asthma - basis of a future warning system for central Phoenix
}

\author{
R. Dimitrova ${ }^{1}$, N. Lurponglukana ${ }^{2}$, H. J. S. Fernando ${ }^{1}$, G. C. Runger ${ }^{2}$, P. Hyde ${ }^{3}$, B. C. Hedquist ${ }^{3}$, J. Anderson ${ }^{3}$, \\ W. Bannister ${ }^{4}$, and W. Johnson ${ }^{4}$ \\ ${ }^{1}$ Environmental Fluid Dynamics Laboratories, Civil Engineering \& Geological Sciences, University of Notre Dame, \\ Notre Dame, IN, USA \\ ${ }^{2}$ Center for Health Information and Research, Arizona State University, Tempe, AZ, USA \\ ${ }^{3}$ School for Engineering of Matter, Transport and Energy, Arizona State University, Tempe, AZ, USA \\ ${ }^{4}$ Industrial Engineering, Arizona State University, Tempe, AZ, USA
}

Correspondence to: R. Dimitrova (reneta.dimitrova@ nd.edu)

Received: 16 June 2011 - Published in Atmos. Chem. Phys. Discuss.: 25 October 2011

Revised: 27 January 2012 - Accepted: 17 February 2012 - Published: 5 March 2012

\begin{abstract}
Statistically significant correlations between increase of asthma attacks in children and elevated concentrations of particulate matter of diameter 10 microns and less $\left(\mathrm{PM}_{10}\right)$ were determined for metropolitan Phoenix, Arizona. Interpolated concentrations from a five-site network provided spatial distribution of $\mathrm{PM}_{10}$ that was mapped onto census tracts with population health records. The case-crossover statistical method was applied to determine the relationship between $\mathrm{PM}_{10}$ concentration and asthma attacks. For children ages 5-17, a significant relationship was discovered between the two, while children ages $0-4$ exhibited virtually no relationship. The risk of adverse health effects was expressed as a function of the change from the 25th to 75 th percentiles of mean level $\mathrm{PM}_{10}\left(36 \mu \mathrm{g} \mathrm{m}^{-3}\right)$. This increase in concentration was associated with a $12.6 \%$ (95\% CI: $5.8 \%, 19.4 \%)$ increase in the log odds of asthma attacks among children ages 5-17. Neither gender nor other demographic variables were significant. The results are being used to develop an asthma early warning system for the study area.
\end{abstract}

\section{Introduction}

The prevalence of asthma, the single-most common chronic childhood disease in developed nations (Janson et al., 1997; Committee TISoAaAiCIS, 1998; WHO, 2003, 2007), has been reported as increasing in many countries (Magnus and Jaakkola, 1997; Akinbami et al., 2002; Burney, 2002; Lin et al., 2005), including in the United States (Brown et al., 1997;
Vollmer et al., 1998; Holgate, 1999; CDC, 2011). The prevalence of asthma in the US has increased $75 \%$ from 1980 until 1994, according the Centers for Disease Control and Prevention (CDC, 1998). Although asthma has become a major public health problem for Americans of all ages, children are particularly affected. According to surveys, the most substantial increase has occurred amongst children of age $0-4 \mathrm{yr}$ (160\%, from 22.2 per 1000 to 57.8 per 1000$)$ and persons of age $5-14 \mathrm{yr}$ (74\%, from 42.8 per 1000 to 74.4 per 1000). Over 10 million US children under age 18 were diagnosed with asthma in 2008 (CDC, 2008). During the past decade, the statewide prevalence of asthma in Arizona has continued to increase, now being higher than the national average (CDC, 2001, 2010). In Phoenix, Arizona, asthma is a major public health issue amongst children of age 0-19. In 2009, $21 \%$ of youth and $15 \%$ of adults in Arizona have been diagnosed with asthma (ADHS, 2009). Increased asthma is a menace for many growing cities in arid regions, such as Phoenix, and hence the United States Environmental Protection Agency (US EPA) is paying particularly close attention to its causes.

Many studies have reported that measurable excesses in pulmonary function decrements, respiratory symptoms, hospital and emergency department admissions, and mortality in human population are associated with ambient levels of various indicators of $\mathrm{PM}$ exposure, most notably $\mathrm{PM}_{10}$ and $\mathrm{PM}_{2.5}$ (US EPA, 2004). Environmental exposures may increase the risk of developing asthma, and they may also increase the frequency and severity of asthma incidents. 
A number of studies have investigated how short-term exposure to PM is related to mortality or to lung functions and respiratory symptoms. An increase of $\mathrm{PM}_{10}$ results in a greater use of asthma medication, frequent visits to medical practitioners and increase of asthma-related hospital admissions (Schwartz et al., 1993; Lipsett et al., 1997; Peters et al., 1997; Atkinson et al., 1999; Norris et al., 1999, Delfino et al., 2002; Maciejczyk et al, 2004, Monteil, 2008; Yeatts et al., 2009; Scapellato et al., 2009). In these studies the association between asthma attacks and different triggers as such as $\mathrm{PM}_{10}$, ozone $\left(\mathrm{O}_{3}\right)$, nitrogen dioxide $\left(\mathrm{NO}_{2}\right)$, sulfur dioxide $\left(\mathrm{SO}_{2}\right)$, and carbon monoxide (CO) have been investigated. Some reported significant correlations between asthma-related hospital admissions and concentrations of $\mathrm{PM}_{10}$ and $\mathrm{NO}_{2}$ (Lipsett et al., 1997), $\mathrm{PM}_{10}$ and $\mathrm{SO}_{2}$ and/or $\mathrm{SO}_{4}$ (Peters et al., 1997; Atkinson et al., 1999) or $\mathrm{PM}_{2.5}$ or $\mathrm{PM}_{10}$ and $\mathrm{CO}$ (Norris et al., 1999; Sheppard et al., 1999) whereas others, using multi-pollutant models, contend that asthma is related to PM concentrations only (Nauenberg and Basu, 1999; Tolbert et al., 2000). All studies that used single-pollutant models have reported significant association of particles and asthma admissions (Schwartz et al., 1992; Maciejczyk et al., 2004; Monteil, 2008; Scapellato et al., 2009). In spite of ozone being considered as an asthma trigger itself some studies indicate that both $\mathrm{PM}_{10}$ and $\mathrm{O}_{3}$ are associated with increases in asthma (Karin et al., 2009), whereas others disagree with this notion (Lipsett et al., 1997; Atkinson et al., 1999; Nauenberg and Basu, 1999). Note that high pollution episodes are largely governed by local conditions, high $\mathrm{O}_{3}$ levels are typical of the summer (generated by photochemical reactions between oxides of nitrogen and volatile organic compounds VOC) and elevated $\mathrm{PM}_{10}$ levels may occur during the summer or winter (as in Arizona and California for example). Many of the epidemiologic studies on $\mathrm{PM}_{10}$ morbidity have been conducted under relatively high $\mathrm{PM}_{10}$ levels, but there are studies that dealt with $\mathrm{PM}_{10}$ concentrations as low as $50 \mu \mathrm{g} \mathrm{m}^{-3}$ or below (Jacobs et al., 1997; Nauenberg and Basu, 1999; Sheppard et al., 1999; Tolbert et al., 2000), which are much lower than the USEPA's 24h PM 10 National Ambient Air Quality Standards (NAAQS) of $150 \mu \mathrm{g} \mathrm{m}^{-3}$. Although the causes of childhood asthma are not well understood, air pollution appears to have a clear role in triggering attacks.

A review of historical data of "criteria" pollutants in metropolitan Phoenix shows that $\mathrm{PM}_{10}$ and 8-h ozone concentrations sometimes exceed the NAAQS, but that the two pollutants exhibit distinct seasonal differences. Elevated concentrations of ozone occur in the summer, when $\mathrm{PM}_{10}$ concentrations are at their lowest. Conversely, in the winter ozone concentrations are low, while $\mathrm{PM}_{10}$ concentrations are at their highest. Asthma incidences, expressed as emergency visits and hospitalizations, exhibit the same wintersummer dichotomy as $\mathrm{PM}_{10}$ concentrations, suggesting that of the two pollutants, the major asthma trigger is $\mathrm{PM}_{10}$, not ozone. Other well-known asthma triggers, such as tempera- ture, humidity, and aeroallergens, were eliminated from consideration in this work for the following reasons. The winter temperature regimes in Phoenix are of two types: (1) warm, sunny days with light winds and with clear cold nights, brought on by strong high pressure systems and (2) windier, cloudy days, with relatively high humidity and with not infrequently with some precipitation, associated with the passage of Pacific cold fronts. Periods of high pressure dominate throughout the winter, with the "cold-front" weather comprising a small minority of the days (less than $30 \%$ of the days). Elevated $\mathrm{PM}_{10}$ concentrations occur only in the first regime. Even though elevated humidity may itself act as an asthma trigger, the warning system envisioned in this work is necessarily dependent on continuous monitoring of particulates concentrations. As far as aeroallergens are concerned, heavily pollinating trees and shrubs are rare in the desert winter; moreover, their concentrations can only be determined through grab sampling with subsequent microscopic analysis. Therefore, it is instructive to investigate how asthma is related to $\mathrm{PM}_{10}$, irrespective of other pollutants. To this end, the US EPA awarded a challenge grant to Arizona Department of Environmental Quality (ADEQ) to study how $\mathrm{PM}_{10}$ is correlated with asthma occurrences. $\mathrm{PM}_{10}$ is comprised of both fine particles less than 2.5 microns $\left(\mathrm{PM}_{2.5}\right)$ and coarse particles (smaller than 10 and larger than 2.5 microns). Note that $\mathrm{PM}_{2.5}$ also can be a trigger, but insufficient data is available from the area to study this aspect. Many studies consider only fine particles, but coarse particles, which are of mainly geological origin, contribute significantly to the total mass of $\mathrm{PM}_{10}$ in arid environments. In metropolitan Phoenix in 2005 and 2006, for example, the four air monitoring sites with both $\mathrm{PM}_{10}$ and $\mathrm{PM}_{2.5}$ monitors had an average ratio of $\mathrm{PM}_{2.5}$ to $\mathrm{PM}_{10}$ of 0.28 , considerably higher than the $\mathrm{PM}_{2.5} / \mathrm{PM}_{10}$ mass ratios of 0.1 to 0.17 reported in most other studies (Cowherd and Kuykendal, 1996; Countess and Richard, 2003; Pace, 2005; Ono, 2005; MRI, 2005, 2006). While we acknowledge that a complex mix of gaseous, semivolatile, and particulate pollutants and their physicochemical properties contribute to health outcomes, in the present study we concentrated on $\mathrm{PM}_{10}$, as this is the principal pollutant that exceeds NAAQS during late autumn and winter. It was hoped to develop an association between $\mathrm{PM}_{10}$ and asthmarelated hospital admittances so that an early warning system could be developed for Phoenix based on predicted $\mathrm{PM}_{10}$ concentrations. The results of the present study are also applicable to climatologically similar urban areas, for example, many southern California cities (Cal/EPA, 2006), Salt Lake City, Utah, Denver, Colorado, El Paso, Texas, and so on.

The interpolation of $\mathrm{PM}_{10}$ measurements from a five-site network of continuous monitors enabled the use of casecrossover statistical method to be applied to census-tractbased health records to determine the relationship between $\mathrm{PM}_{10}$ and asthma incidences. Spatial concentration fields of $\mathrm{PM}_{10}$ for 2005 and 2006 were constructed and then linked with the public health data. Inverse Distance Weighting 


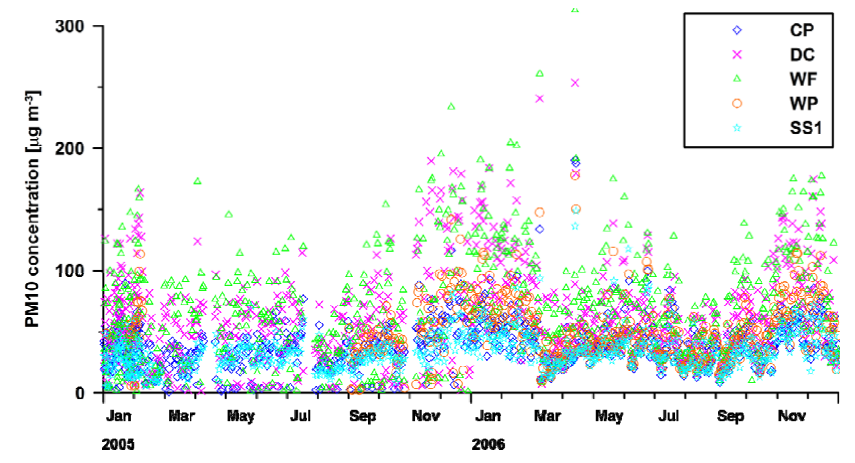

Fig. 1. 24-h averaged $\mathrm{PM}_{10}$ from five permanent monitors in central Phoenix (Abbreviations: CP - Central Phoenix, DC - Durango complex, WF - West 43rd Avenue, WP - West Phoenix, SS1 Supersite).

(IDW) was used in this study, but it was evaluated and verified by the more sophisticated Ordinary Kriging (OK) with additional data from an expanded network in December 2007 through February 2008.

The goal of this study is to clarify the association of incidents of asthma attacks (as identified by the primarily emergency department visits and hospital admissions; however for brevity are called asthma incidents further) with elevated concentrations of particulate matter 10 microns and smaller $\left(\mathrm{PM}_{10}\right)$. It breaks new ground in two ways: it demonstrates how adequate concentration fields can be derived by interpolation from a sparse (five site) network of continuous $\mathrm{PM}_{10}$ monitors; and, it specifically focuses on associations of childhood asthma with $\mathrm{PM}_{10}$, a focus that could lead to the development of a warning system for the asthmatic children of Phoenix. This work complements numerous previous studies on health outcomes of air pollution for particular groups, e.g. pregnant women and infants (Viana et al., 2008) and by specific causations e.g. congenital defects or prematurity (Dolk and Vrijheid, 2003; Hansen et al., 2006).

\section{Data and methods}

\subsection{Air quality data}

Spatially distributed $\mathrm{PM}_{10}$ concentrations were estimated by interpolating the measured concentrations from a permanent network of five continuous monitors (hourly data) in central Phoenix operated by two public agencies: Maricopa County Department of Air Quality (MCDAQ) and Air Quality Division of the Arizona Department of Environmental Quality (ADEQ). As the only NAAQS of interest here was for the 24-h average of $\mathrm{PM}_{10}$, and the aim was to examine the relationship between $\mathrm{PM}_{10}$ concentrations and daily asthma incidents, daily averages of $\mathrm{PM}_{10}$ were calculated from reported hourly averages measured by the permanent monitors. Each of these permanent sites has its unique combination of local emission sources and susceptibility to urban transport that together, along with the desert background, result in the measured concentrations. Each has its own degree of representativeness as a footprint: i.e. how far away from the monitor do the measured concentrations actually prevail? The $\mathrm{PM}_{10}$ variation among these five sites can be seen in their 24-h averages, given as a time series for 2005-2006 (Fig. 1). The names of the monitoring stations are given in the captions of Figs. 1 and 2.

West 43rd Avenue (WF) and Durango complex (DC) sites have $\mathrm{PM}_{10}$ concentrations considerably higher than the other three, especially in winter, and both have a relatively high frequency of violations of NAAQS. This pattern can be understood in light of dense localized emissions from the extractive and material handling industries along the Salt River combined with their low-elevation location that places the area downwind of most nocturnal and early morning urban emissions. They represent the worst $\mathrm{PM}_{10}$ air quality in metropolitan Phoenix.

\subsection{Asthma data}

The primary health data were obtained from the Arizona Department of Health Services (ADHS) for the asthma incidents reported between 1 January 2004 and 31 December 2006. Incident locations are based on the census track of the patient's home address. The analysis focuses on school-age children, and it is assumed that school locations are near the home census tract. These data include both hospitalization and emergency room visits throughout the Maricopa County, as well as patient demographics such as gender and age. In spite of standard quality control, additional steps were taken to ensure the accuracy of the data. For example, there were cases where the same patient went to an emergency room and was later admitted to the hospital. This single patient had multiple records on the same day with his status changing from emergency to inpatient. Such redundant records were deleted to leave all but a single asthma incident. Also, those subsequent medical encounters occurring sufficiently long after the initial visit were considered to be a distinct incident. This time period is commonly referred to as a "washout" period or "gap". Several washout periods were explored in this study. The change in the number of asthma incidents is minimal for washout periods of 7 to 28 days (from 10095 to 9631). Therefore, a washout period of seven days was selected because it is a common choice for studies such as this. If the same person had multiple records within the seven days, only the initial record was kept.

Preliminary analyses defined the demographic groups, sample size, data cleaning strategies, and the precise study area for the final analyses of the work presented here. The present study focused on asthma incidents within the 168 census tracts of metropolitan Phoenix from 1 January 2005 through 30 September 2006 because of lack of full records of air quality data for 2004. All asthma events 


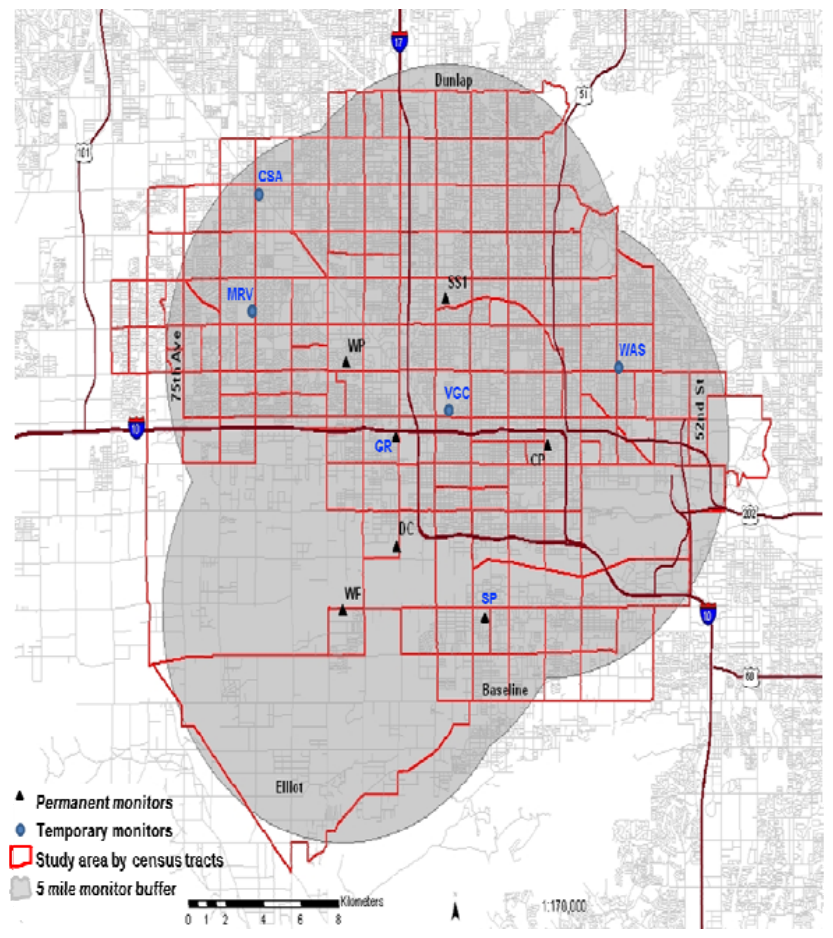

Fig. 2. Study domain and location of the monitors: permanent (data used in the health study) and temporary (data used for validation of spatial interpolation method). Abbreviations: CP - Central Phoenix, DC - Durango complex, WF - West 43rd Avenue, WP - West Phoenix, SS1 - Supersite; GR - Greenwood; SP - South Phoenix; CSA - Community Service of AZ; MRV - Maryvale; VGC - Valley Garden Center; WAS - Weaver's Auto Service).

within five miles of a continuous $\mathrm{PM}_{10}$ monitor were included (Fig. 2). This study area accounted for $75 \%$ of the total asthma incidents of Maricopa County.

\subsection{Interpolation of $\mathrm{PM}_{10}$ concentrations}

Practical constraints make it impossible to obtain data at every desired point. Thus, interpolation is imperative for graphing, analyzing and understanding the spatial distribution of air pollution throughout the metropolitan area. Inverse distance weighting (IDW) is one of the simplest interpolation methods. A neighborhood in the vicinity of the interpolated point was identified and a weighted average was taken of the observation values within it. The weights are a decreasing function of distance. The user has control over the mathematical form of the weighting function, the size of the neighborhood (expressed as a radius or a number of points), in addition to other options.

As mentioned, Kriging methods were also tested for interpolation, including ordinary kriging. This method utilizes a variogram model to express the spatial variation of data points, and then minimize their error. The word "kriging" is synonymous with "optimal prediction". Ordinary krig- ing $(\mathrm{OK})$ is a geostatistical approach to modeling. Instead of weighting nearby data points by some power of their inverted distance, it relies on the spatial correlation structure of the data to determine the weighting values. This is a more rigorous approach than IDW, as correlation between data points determines the estimated value at an unsampled point. Ordinary kriging makes the assumption of normality among the data points, as well as an unknown constant trend. This differs from simple or universal kriging that assumes a known constant trend and/or model.

In our study, IDW interpolation was used due to lack of enough data points (at least 10) to apply OK. Nevertheless, as discussed later, the adequacy of IDW was established by comparing the two methods over a limited time period; for this, a stop-gap monitoring network was installed to augment continuous monitors (Fig. 2).

Six additional monitors were placed (marked in blue at Fig. 2) - four temporary sites and two permanent ones (GR and SP). The newly established permanent sites began operating in 2007. The four temporary sites were deployed from December 2007 through February 2008. These additional sites enabled the use of $\mathrm{OK}$, and thus enabling evaluation of IDW for the special deployment period and hence for the earlier period with five instead of eleven $\mathrm{PM}_{10}$ monitors.

The interpolated 24-h averaged concentrations were linked to 168 census tract areas in metropolitan Phoenix from 1 January 2005 through 30 September 2006, a period for which complete air monitoring records were available. These data were used further for data analyses and linking with the health data.

\subsection{IDW method verification}

The surfaces of $\mathrm{PM}_{10}$ obtained by both methods were compared, with Fig. 3 being only one example of such comparisons of concentration fields for one particular day $21 \mathrm{De}-$ cember 2007. Values from five $\mathrm{PM}_{10}$ monitors were used in IDW and eleven in OK. Differences for the 24-h average $\mathrm{PM}_{10}$ can be seen in the northwest, where the additional data led to reduced $\mathrm{PM}_{10}$ concentrations (Fig. 3).

In a comparison between the two interpolation methods for December 2007 (Fig. 4), it can be seen that better agreement is achieved in the central part of the study area, in close proximity to the five permanent $\mathrm{PM}_{10}$ monitors. The overall difference between the two methods in the central part of the study domain is less than $8 \%$. Mean Absolute Error is in range $0-5 \mu \mathrm{g} \mathrm{m}^{-3}$ and the average concentration is $64 \mu \mathrm{g} \mathrm{m}^{-3}$ (in range $56-72 \mu \mathrm{g} \mathrm{m}^{-3}$ ). Even though the OK interpolation had the benefit of two additional monitors in the central part of the study area (GR and VGC), the differences between the interpolated surfaces was surprisingly low. Therefore, the five monitors used with IDW interpolation are considered representative of the spatial concentration gradients in central Phoenix. As expected, greater disagreement 


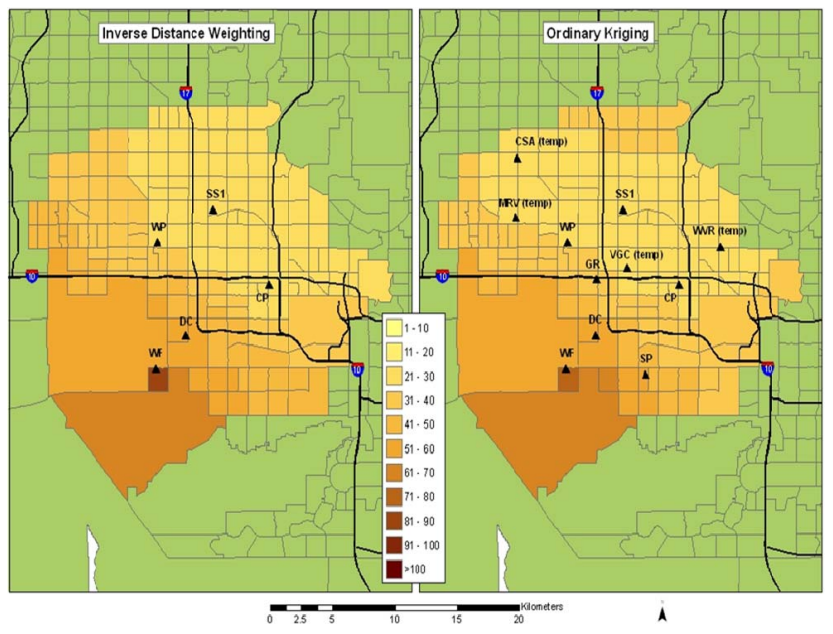

Fig. 3. $\mathrm{PM}_{10} 24-\mathrm{h}$ concentration obtained $\left(\mu \mathrm{g} \mathrm{m}^{-3}\right)$ using two different methods: IDW and OK; 21 December 2007.

occurs at the outer edges of the study area, in census tracts close to the temporary $\mathrm{PM}_{10}$ monitors.

Some statistical measures (description is given in Appendix A) for IDW interpolation performance, compared with the OK method, are listed in Table 1. Spatial averaged was made over the entire study area (Fig. 4) in addition to time averaged, and the minimum and maximum values within the study domain are also shown. The averaged bias are positive (IDW slightly overestimates the concentrations provided by OK method), but negative bias (underestimation) are also seen for a few census tracts. The average errors are less than $15 \%$ (NME, MFR) and NMSE is less than $1 \%$. The index of agreement between both surfaces is reasonably high $(82.3 \%)$ with a correlation coefficient 0.68 .

In all, the IDW was shown to be sufficiently accurate to produce spatial concentration fields for the health analysis within five miles of each monitoring location, with the resulting interpolation domain for health study shown in Fig. 2.

\subsection{Methods of analysis}

The case-crossover approach (Maclure, 1991), similar to crossover and matched-pair case-control studies (Hosmer and Lemeshow, 2000), has been developed to study transient, short-term exposure effects on the risk of rare acute events. The "case" is a person with the event of interest at a certain time called the "hazard period", while the control (called the referent) is the same person at a different time called the "control period". The key advantage of this design is that each case comes with its own control. The exposure information for each subject during the hazard period is compared with the exposure information during the control or "referent" period. With an appropriate referent period, the case-

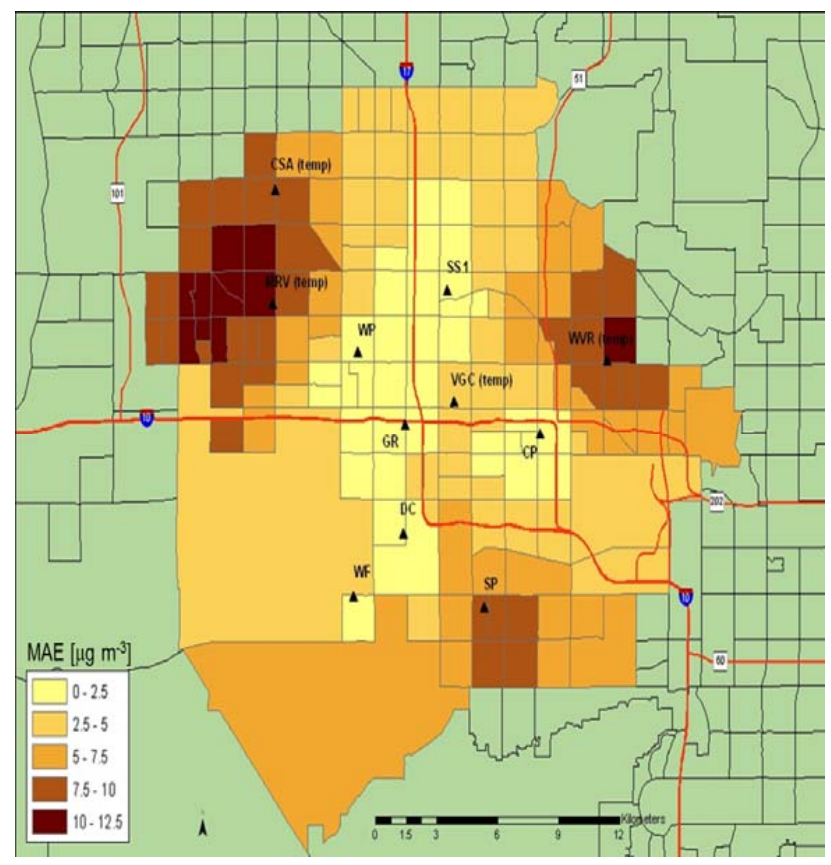

Fig. 4. Mean Absolute Error $\left(\mu \mathrm{g} \mathrm{m}^{-3}\right)$ for December 2007 between IDW and OK methods - based on daily maps. (Abbreviations: CP - Central Phoenix, DC - Durango complex, WF - West 43rd Avenue, WP - West Phoenix, SS1 - Supersite; GR - Greenwood; SP - South Phoenix; CSA - Community Service of AZ; MRV - Maryvale; VGC - Valley Garden Center; WAS - Weaver's Auto Service).

crossover analysis controls for long-term trends, seasonal effects, and other covariates that change slowly with time.

In the bidirectional approach, Bateson and Schwartz (1999, 2001) examined sampling methods for the referent to reduce the bias by selecting from either side of the event. Also, disjoint referent periods have been recommended for bias concerns (Levy et al., 2001). With a control close in time to the event, these methods avoid confounding due to subject differences and other long-term effects such as seasonality. A balance must be maintained, however, between a control too close in time that generates autocorrelation and a control too far removed in time that confounds long-term effects. Alternatives within a few weeks of the events have been considered. Neas et al. (1999) studied daily mortality in Philadelphia where the case period was the $48 \mathrm{~h}$ ending at midnight on the day of death (Schwartz and Dockery, 1992) and the control period was the same day of week 7, 14, or 21 days before and after the case period. Medina-Ramon et al. (2006) used a matching scheme from Bateson and Schwartz $(1999,2001)$ and a timestratified partition by Lumley and Levy (2000) that chose control days only in the same month as the hospital admission for chronic obstructive pulmonary disease (http://www. nhlbi.nih.gov/health/dci/Diseases/Copd/Copd_WhatIs.html). Lin et al. (2005) calculated a one to seven day exposure 
Table 1. Performance statistics for IDW validation.

\begin{tabular}{lrrr}
\hline Metrics & Average & Minimum & Maximum \\
\hline Mean Bias - MB $\left(\mu \mathrm{g} \mathrm{m}^{-3}\right)$ & 4.5 & -1.5 & 10.9 \\
Mean Absolute Error - MAE $\left(\mu \mathrm{g} \mathrm{m}^{-3}\right)$ & 5.3 & 0.5 & 10.9 \\
Root Mean Squared Error - RMSE $\left(\mu \mathrm{g} \mathrm{m}^{-3}\right)$ & 6.3 & 0.6 & 12.5 \\
Normalized Mean Bias - NMB $(\%)$ & 14.4 & -0.5 & 26.8 \\
Normalized Mean Error - NME (\%) & 15.8 & 6.6 & 27.5 \\
Mean Fractional Bias - MFB (\%) & 13.4 & -3.7 & 34.8 \\
Mean Fractional Error - MFE $(\%)$ & 15.1 & 1.5 & 34.8 \\
Normalized Mean Square Error - NMSE $(\%)$ & 0.2 & 0.001 & 0.6 \\
Index of Agreement - IA (\%) & 82.3 & 50.9 & 99.8 \\
Coefficient of determination - $R^{2}$ & 0.68 & 0.60 & 0.80 \\
\hline
\end{tabular}

average ending on the admission date as the exposure in the case period with control periods of two weeks before and after the admission date. Peel et al. (2005) studied the hospital admissions associated with ambient air pollution levels and respiratory health effects. The case period of three-day moving averages of pollutant concentration was selected within two weeks of the case period. The average was the average of pollutant concentrations on the same day as the visit, one day before, and two days before.

A case-crossover study was conducted in the present work with the referent period based on a time-stratified scheme to control confounding effects from seasonality and time trends. The referents were selected within a 28-day stratum (four weeks) at 7, 14, and 21 days before or after the case (same day of the week), provided they occurred in the same stratum. Consequently, each case has three controls.

Several potential primary and secondary effects were considered. The first primary effect was the 24-h average $\mathrm{PM}_{10}$ concentration from the IDW interpolation of the observations on the day of the asthma event. The second primary effect, called the "lag", was the average $\mathrm{PM}_{10}$ concentration one to five days before the event, here the "lag" being the delay in days between the exposure and the health effect. For example, a one-day lag is the average $\mathrm{PM}_{10}$ of the previous day and the event day, abbreviated as "lag1". Secondary effects were the covariates of age, gender, ethnicity, and place of service. Place of service is a categorical variable with two values: emergency and inpatient. Age is encoded into four categories: $0-4,5-9,10-14$, and $15-17$ yr. Ethnicity followed US Census Bureau definitions. Preliminary analysis detected no differences between places of service; therefore, this variable was not considered further. Even though the case-crossover design controls for the main effects of these patient-level covariates, the interactions of these covariates with the event-day $\mathrm{PM}_{10}$ concentration and its various lags were also considered.

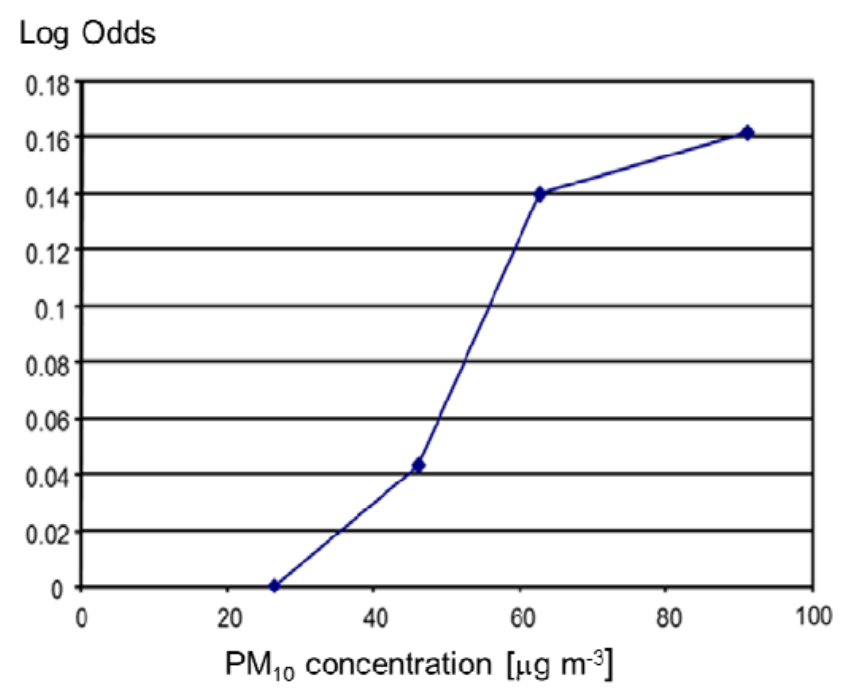

Fig. 5. Natural logarithm of the odds ratio (log odds) of asthma incidents versus categories of Dailymean $\mathrm{PM}_{10}$ concentrations $\left(\mu \mathrm{g} \mathrm{m}^{-3}\right)$. Categories are defined by quartiles of $\mathrm{PM}_{10}$ and represented by the median $\mathrm{PM}_{10}$ within the category.

The analysis considered subsets of these covariates through conditional logistic regression (Hosmer and Lemeshow, 2000). All-subsets regression was used to investigate models with demographic variables and with and without interaction (cross-product) terms. Short description of terms used in this analysis is listed below.

\subsection{Statistical model validation}

The model used for the results discussed in the following section was a conditional linear regression model. The traditional assumption for a logistic regression model is linear relationship of the log odds to the predictor variables. A full explanation of the mathematical formulation is given in Appendix B. However, to assess the linearity assumption a model without any linear or monotonic assumptions was 


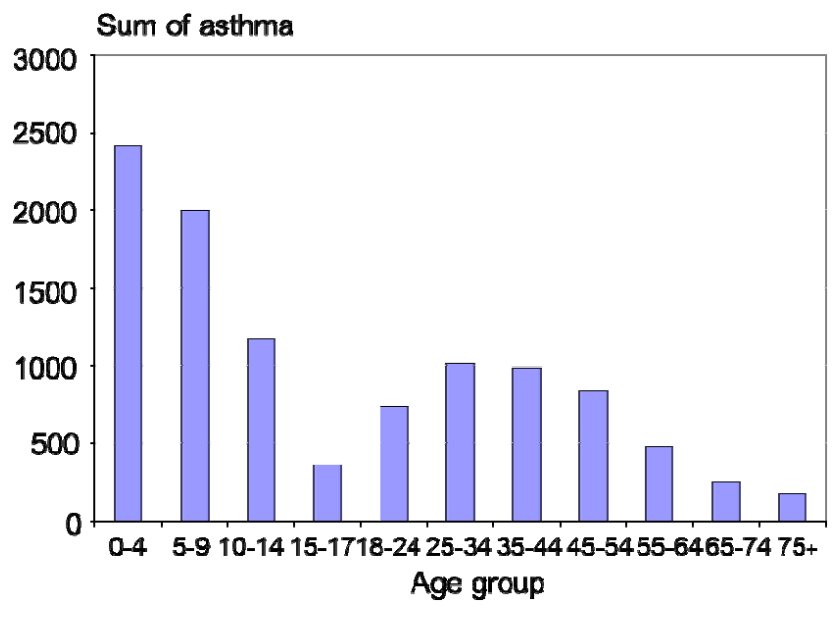

Fig. 6. Asthma incidences by age within five miles of $\mathrm{PM}_{10}$ monitoring sites.

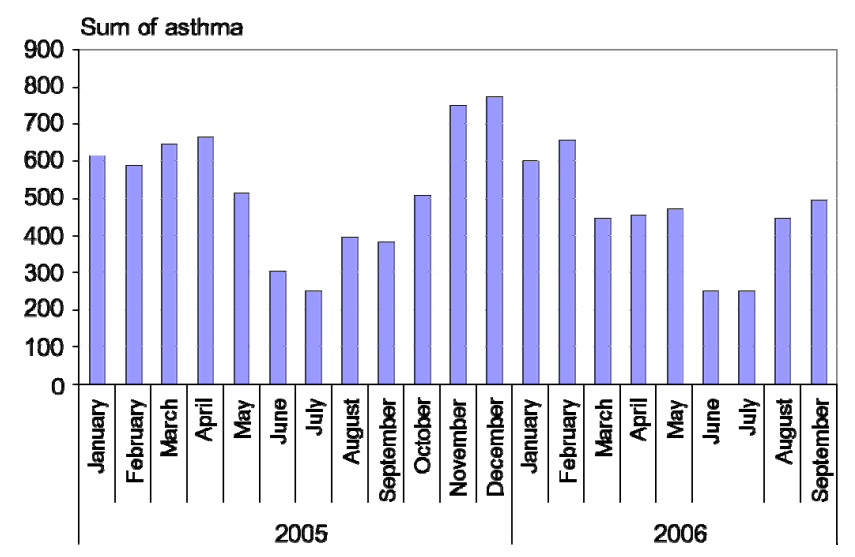

Fig. 7. Asthma incidences by month within five miles of $\mathrm{PM}_{10}$ monitoring sites.

employed for validation. A recommended approach is to use categorical variables to define ranges of $\mathrm{PM}_{10}$ (Steenland and Deddens, 2004) and model the log odds. The categories are defined from the quartiles because results are often reported as the effect from a change equal to the interquartile range of $\mathrm{PM}_{10}$. The $\mathrm{PM}_{10}$ concentrations were linked to asthma events by the indicator variables in the regression models with the first quartile as the baseline. The odds ratio can be readily interpreted as a measure of how likely or unlikely it is for an asthma incident to be associated with a daily mean $\mathrm{PM}_{10}$ concentration. Odds ratios greater than 1.0 imply that the asthma event is more likely to be associated with the $\mathrm{PM}_{10}$ concentration and vice versa. The natural logarithm of the odds ratio (log odds) of an asthma incident, "log odds" of the y-axis, plotted against the median $\mathrm{PM}_{10}$ in the category in Fig. 5, illustrates the monotonic, approximately linear relationship of the $\log$ odds versus the quartiles of the daily mean.

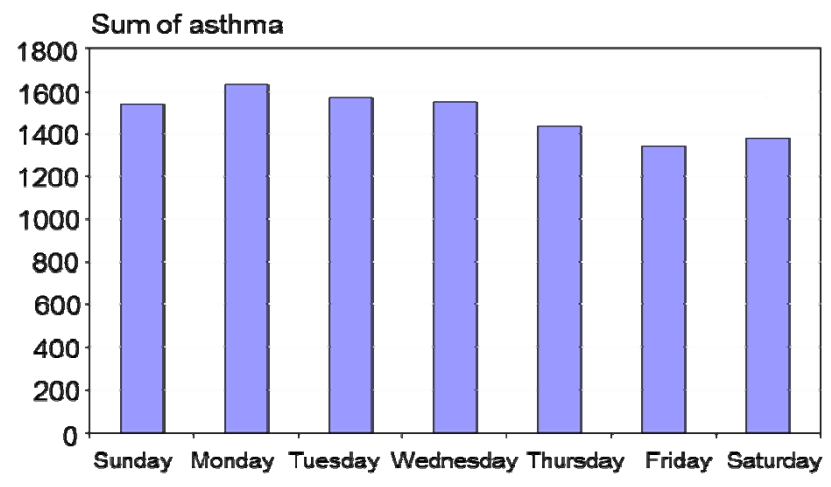

Fig. 8. Asthma incidences by the day of the week within five miles of $\mathrm{PM}_{10}$ monitoring sites.

Table 2. Model statistics for each main effect (preschool age group excluded).

\begin{tabular}{lrrr}
\hline Variable & Coefficient & Chi Square & $p$-Value \\
\hline Dailymean & 0.00331 & 11.7859 & 0.0006 \\
Lag1 & 0.00272 & 6.7347 & 0.0095 \\
Lag2 & 0.00103 & 0.9352 & 0.3335 \\
Lag3 & 0.00112 & 1.2531 & 0.263 \\
Lag4 & 0.00244 & 5.7373 & 0.0166 \\
Lag5 & 0.00231 & 4.1032 & 0.0428 \\
Lag6 & 0.00212 & 4.0581 & 0.044 \\
Lag7 & 0.00168 & 2.522 & 0.1123 \\
Lag8 & -0.0001995 & 0.031 & 0.8602 \\
\hline
\end{tabular}

\section{Results and discussion}

Asthma incidents were described by the age group, day of the week, and month, resulting in a dataset containing about 10000 events within a five-mile radius from the nearest monitoring station (Figs. 6-8). About two thirds of these events are for ages $0-17$.

The event day $\mathrm{PM}_{10}$, also called "Dailymean", and lag variables were considered in a statistical analysis as shown in Table 2. Only the $\mathrm{PM}_{10}$ on the day of the event (Dailymean) and the lag $1 \mathrm{PM}_{10}$ are significant at a $1 \%$ significance level. Although there variability is the $p$-values if one applied a traditional Bonferroni correction to adjust the significance level for the nine multiple tests, one might require a $p$-value less than $0.05 / 9=0.0056$ and only the Dailymean is significant. Consequently, further analysis was restricted to the Dailymean as the principal covariate of $\mathrm{PM}_{10}$.

An all-subsets regression considered Dailymean, the demographic variables, and interactions in models for the health effects. The conditional regression analysis indicated that the Dailymean alone was a sufficient covariate for asthma incidents, but that age was a potential effect modifier. The age effect is discussed further below. No effect due to gender or the other demographic variables was detected. 
Table 3. Case-crossover statistics relating asthma incidents to $\mathrm{PM}_{10}$ concentrations in Phoenix metropolitan.

\begin{tabular}{lrrrrr}
\hline Case & Coefficient & St. Error & $p$-value & Adjusted OR* & $95 \%$ CI \\
\hline All events & 0.0025 & 0.00075 & 0.0010 & 1.094 & $(1.041,1.147)$ \\
Preschool only & -0.000092 & 0.00121 & 0.4457 & 0.997 & $(0.911,1.082)$ \\
Preschool excluded & 0.0033 & 0.00096 & 0.0006 & 1.126 & $(1.058,1.194)$ \\
\hline
\end{tabular}

The case-crossover statistics are presented and discussed for three different samples of the childhood asthma population: all events (ages 0-17), preschool events only (ages 0-4) and events excluding the preschool group (Ages 5-17). The results from the different samples exhibit certain differences (Table 3).

The coefficients in Table 3 vary considerably indicating somewhat different relationships between the increased probability of an asthma event and the event-day $\mathrm{PM}_{10}$ concentrations among different subpopulations, especially for the case of preschool only (negative coefficient).

The change in 24-h average $\mathrm{PM}_{10}$ from the 25th to 75th percentile, defined as the interquartile range (IQR), is $36 \mu \mathrm{m}^{-3}$. A change in $\mathrm{PM}_{10}$ concentration equal to the IQR is commonly used as the change magnitude to report the adjusted odds ratio. As shown in Table 3 the adjusted odds ratio for all events is estimated to be 1.094 , meaning that every additional $36 \mu \mathrm{g} \mathrm{m}^{-3}$ of Dailymean $\mathrm{PM}_{10}$ is estimated to increase the odds ratio of an asthma incident for a person under $17 \mathrm{yr}$ old by $9.4 \%(4.1 \%, 14.7 \%)$, where the values in parentheses provide a $95 \%$ confidence interval. In the preschool group (ages 0-4 yr) only, no effect from Dailymean $\mathrm{PM}_{10}$ was found. The odds ratio was estimated at 0.997 and the estimated change was not significant at $-0.3 \%$ $(-8.9 \%, 8.2 \%)$ with a $95 \%$ confidence interval that contains zero. Further analysis detected a stronger relationship between Dailymean and asthma incidents when the preschool age group was excluded. All-subsets regression again indicated that Dailymean alone was a sufficient covariate for asthma incidents. Every additional $36 \mu \mathrm{g} \mathrm{m}^{-3}$ of Dailymean $\mathrm{PM}_{10}$ increases the odds ratio of an asthma incident for a child in ages $5-17 \mathrm{yr}$ old by $12.6 \%(5.8 \%, 19.4 \%)$ with $95 \%$ confidence intervals in parentheses.

\section{Conclusions}

$\mathrm{PM}_{10}$ concentrations were found to have statistically significant associations with asthma incidents in central Phoenix at the $95 \%$ confidence level. For children ages 5-17 a much stronger effect was noted than determined by previous studies, while preschool children ages $0-4$ exhibited virtually no effects. Previous studies have reported the risk of adverse health effects as a function of the change of Dailymean $\mathrm{PM}_{10}$ from the $25 \%$ to $75 \%$ percentile; in this study the corresponding change was $36 \mu \mathrm{g} \mathrm{m}^{-3}$. This increase in $\mathrm{PM}_{10}$ is associated with a $13 \%$ increase in the probability of asthma incidents among children ages 5-17; gender was insignificant. Note that the concentrations considered are much lower than the 24-h $\mathrm{PM}_{10}$ standard of $150 \mu \mathrm{g} \mathrm{m}^{-3}$. The lack of a preschool effect could be explained by the difficulty of asthma diagnoses at the younger ages and/or their possible spending of more time indoors.

With only a sparse network of five monitoring sites in a large metropolitan area, Inverse Distance Weighting (IDW) interpolation provided an adequate spatial distribution of urban $\mathrm{PM}_{10}$ concentrations efficiently and rapidly. There were differences, but not unacceptably large, between IDW interpolated concentrations and those from the more sophisticated ordinary kriging technique. The kriging interpolation was realized by deploying temporary monitors over a special test period and utilizing concentrations from two permanent sites that began operation in 2007, thus increasing the number of monitors in central Phoenix from five to eleven. Because the two methods produced comparable distributions, and because the period of analysis had only five monitoring sites, inverse distance weighting was the method of choice for this health analysis.

It has been suggested, based on the present study, to install neural networks for each of the permanent monitors to predict $\mathrm{PM}_{10}$ based on several years of prior measurements at each site as well as meteorological predictions for those sites based on a deterministic model (Mammarella et al., 2009; Fernando et al., 2011). The $\mathrm{PM}_{10}$ predictions could be interpolated to a census tract grid, which together with some forecaster intervention and examining could be used to issue health warnings for the area. Such a predictive system would exemplify the use of best-available scientific and technological tools for issuance of health warnings. The proposed methodology has been well-received within the USEPA, as evident from the issuance of funding to develop a pilot health warning system.

\section{Appendix A}

\section{Definitions of statistics}

The following indicators were used for performance evaluation. Here IDW is the value obtained by Inverse Distance 
Weighting method, OK is the value obtained by Ordinary Kriging method, and $\overline{\mathrm{IDW}}$ and $\overline{\mathrm{OK}}$ are the mean values.

$\mathrm{MB}=\frac{1}{N} \sum_{i=1}^{N}\left(\mathrm{IDW}_{i}-\mathrm{OK}_{i}\right)$

(Mean Bias)

$\mathrm{MAE}=\frac{1}{N} \sum_{i=1}^{N}\left|\mathrm{IDW}_{i}-\mathrm{OK}_{i}\right|$

(Mean Absolute Error)

$\mathrm{RMSE}=\sqrt{\frac{\sum_{i=1}^{N}\left(\mathrm{IDW}_{i}-\mathrm{OK}_{i}\right)^{2}}{N}}$

(Root Mean Square Error)

$\mathrm{NMB}=\frac{\sum_{i=1}^{N}\left(\mathrm{IDW}_{i}-\mathrm{OK}_{i}\right)}{\sum_{i=1}^{N} \mathrm{OK}_{i}} 100 \%$

(Normalized Mean Bias)

$\mathrm{NME}=\frac{\sum_{i=1}^{N}\left|\mathrm{IDW}_{i}-\mathrm{OK}_{i}\right|}{\sum_{i=1}^{N} \mathrm{OK}_{i}} 100 \%$

(Normalized Mean Error)

$\mathrm{MFB}=\sum_{i=1}^{N}\left(\frac{\left(\mathrm{IDW}_{i}-\mathrm{OK}_{i}\right)}{0.5 *\left(\mathrm{IDW}_{i}+\mathrm{OK}_{i}\right)}\right) 100 \%$

(Mean Fractional Bias)

$\mathrm{MFE}=\sum_{i=1}^{N}\left(\frac{\left|\mathrm{IDW}_{i}-\mathrm{OK}_{i}\right|}{\left|\mathrm{IDW}_{i}+\mathrm{OK}_{i}\right| * 0.5}\right) 100 \%$

(Mean Fractional Error)

$\mathrm{NMSE}=\frac{\sum_{i=1}^{N}\left(\mathrm{IDW}_{i}-\mathrm{OK}_{i}\right)^{2}}{\sum_{i=1}^{N} \mathrm{IDW}_{i} \sum_{i=1}^{N} \mathrm{OK}_{i}} 100 \%$

(Normalized Mean Square Error)

$\mathrm{IA}=1-\frac{\sum_{i=1}^{N}\left(\mathrm{IDW}_{i}-\mathrm{OK}_{i}\right)^{2}}{\sum_{i=1}^{N}\left(\left(\mathrm{IDW}_{i}-\overline{\mathrm{OK}}\right)^{2}+\left(\mathrm{OK}_{i}-\overline{\mathrm{OK}}\right)^{2}\right)}$

(IA Index of Agreement)

$$
R^{2}=\frac{\left[\sum_{i=1}^{N}\left(\mathrm{IDW}_{i}-\overline{\mathrm{IDW}}\right)\left(\mathrm{OK}_{i}-\overline{\mathrm{OK}}\right)\right]^{2}}{\sum_{i=1}^{N}\left(\mathrm{IDW}_{i}-\overline{\mathrm{IDW}}\right)^{2} \sum_{i=1}^{N}\left(\mathrm{OK}_{i}-\overline{\mathrm{OK}}\right)^{2}}
$$

(RSQ Coefficient of determination)

\section{Appendix B}

\section{Description of the case-crossover method}

Here we present a general discussion of the odds ratio the typical statistic employed in reporting the results from the case-crossover method, and continues with a discussion of conditional logistic regression, and it concludes with the specific mathematical formulation of the odds ratio used in the present work.

The odds ratio is a measure of effect size particularly important in logistic regression. It is defined as the ratio of the odds of an event occurring in one group to the odds of it occurring in another group, or to a sample-based estimate of that ratio. These groups might be men and women, an experimental group and a control group, or any other dichotomous classification. If the probabilities of the event in each of the groups are $p$ (first group) and $q$ (second group), then the odds ratio is:

$\frac{p /(1-p)}{q /(1-q)}=\frac{p(1-q)}{q(1-p)}$

An odds ratio of 1 indicates that the condition or event under study is equally likely in both groups. An odds ratio greater than 1 indicates that the condition or event is more likely in the first group. And an odds ratio less than 1 indicates that the condition or event is less likely in the first group. The odds ratio must be greater than or equal to zero. As the odds of the first group approaches zero, the odds ratio approaches zero. As the odds of the second group approaches zero, the odds ratio approaches positive infinity.

The increased use of logistic regression in medical and social science research means that the odds ratio is commonly used as a means of expressing the results in some forms of clinical trials, in survey research, and in epidemiology, such as in case-control studies. It is often abbreviated "OR" in reports. When data from multiple surveys is combined, it will often be expressed as "pooled OR".

Conditional logistic regression has been widely applied to model stratified data, such as case-crossover analysis and case-control analysis (Lin et al., 2005, Neas et al., 1999, Figuerias et al., 2005, and Redelmeier and Tibishirani, 1997). Logistic regression is a form of regression used when the response is binary. Let $\boldsymbol{x}$ be a vector of $k$ predictor variables (or covariates). Let $Y$ be a binary response $(y=0$ or $y=1)$. The conditional probability that $Y=1$ is $P(Y=1 \mid x)=p(x)$. The logit of the logistic regression model is

$f(\boldsymbol{x})=\beta_{0}+\beta_{1} x_{1}+\ldots+\beta_{p} x_{p}$ 
so the logistic regression model is

$$
p(\boldsymbol{x})=\frac{e^{f(x)}}{1+e^{f(x)}}
$$

Let consider the system that has a binary response $y$ and a two-level covariate $x, x=0$ or $x=1$. The logit transformation is defined in terms of $p(\boldsymbol{x})$ as

$$
f(x)=\ln [p(x) /(1-p(x))]=\beta_{0}+\beta_{1} x
$$

The conditional logistic regression works in similar fashion as regular logistic regression. It considers the stratification structure in the data specifying which individuals belong to which strata. Suppose there are $K$ strata with $n_{k}$ subjects in the $k$ th-stratum, where $k=1,2,3, \ldots, K$ There are $n_{1 k}$ case subjects, $n_{0 k}$ control subjects, and $n_{k}=n_{1 k}+n_{0 k}$ (Hosmer and Lemeshow, 2000). The logistic regression model can be shown as

$$
p_{k}(\boldsymbol{x})=\frac{e^{\beta_{0 k}+\boldsymbol{\beta}^{\prime} x}}{1+e^{\beta_{0 k}+\boldsymbol{\beta}^{\prime} x}}
$$

where is a nuisance parameter with the contribution of all terms constant within the $k$ th-stratum, $\beta^{\prime}=\left(\beta_{1}, \beta_{2}, \ldots, \beta_{k}\right)$ are the vector of coefficients of covariates, $\boldsymbol{x}$.

To analyze case-crossover design using conditional logistic regression, the PROC PHREG from SAS® statistical software package was used. Conditional logistic regression can be performed by the PHREG procedure by using the discrete logistic model and forming a stratum for each matched set. The dummy survival times are needed to be created so that all the cases in a matched set have the same event time value, and the corresponding controls are censored at later times.

From the logistic regression model defined earlier. The odds of $y=1$ when the covariates have values $x_{1}$ is defined as $p(1) /(1-p(1))$ and the odds of $y=\mathrm{v} 0$ when the covariates have values $x_{0}$ is defined as $p(0) /(1-p(0))$. The odds ratio (OR) is defined as the odds for $x_{1}$ to the odds for $x_{0}$, odds ratios (OR) can be shown to be

$$
\begin{aligned}
& \mathrm{OR}=\frac{p(1) /[1-p(1)]}{p(0) /[1-p(0)]} \\
& =\frac{\left(\frac{e^{\beta_{0}+\beta_{1}}}{1+e^{\beta_{0}+\beta_{1}}}\right) /\left(\frac{1}{1+e^{\beta_{0}+\beta_{1}}}\right)}{\left(\frac{e^{\beta_{0}}}{1+e^{\beta_{0}}}\right) /\left(\frac{1}{1+e^{\beta_{0}}}\right)} \\
& =\frac{e^{\beta_{0}+\beta_{1}}}{e^{\beta_{0}}}=e^{\left(\beta_{0}+\beta_{1}\right)-\beta_{0}}=e^{\beta_{1}}
\end{aligned}
$$

The odds ratio is an associate measure of how much more likely (an odds ratio $>1$ ), unlikely (an odds ratio $<1$ ), or equally likely (an odds ratio $=1$ ) it is for the response to present under $x_{1}$ than under conditions $x_{0}$.
Acknowledgements. The present work was carried out within the Arizona Children's Health Challenge Grant Project supported by US Environmental Protection Agency (USEPA) in partnership with the Arizona Department of Environmental Quality (ADEQ) and the Arizona Department of Health Services (ADHS).

Edited by: A. Baklanov

\section{References}

Akinbami, L. and Schoendorf, K.: Trends in childhood asthma: prevalence, health care utilization and mortality, Pediatrics, 110, 315-22, 2002.

Arizona Department of Health Services, Division of Public Health - Asthma - AZ Fast Fact, available at: http://azdhs.gov/tobaccofreeaz/resources/pdf/btcd/Asthma\% 20Fact\%20Sheet.pdf, last access: 28 February 2012, 2009.

Atkinson, R. W., Anderson, H. R., Strachan, D. P., Bland, J. M., Bremmer, S. A., and Ponce de Leon A.: Short-term associations between outdoor air pollution and visits to accident and emergency departments in London for respiratory complaints, Eur. Respir. J., 13, 257-265, ISSN 0903-1936, 1999.

Bateson, T. and Schwartz, J.: Control for seasonal variation and time trend in case-crossover study of acute effects of environmental exposures, Epidemiology, 10, 539-544, 1999.

Bateson, T. and Schwartz, J.: Selection bias and confounding in case-crossover analyses of environmental time-series data, Epidemiology, 12, 654-661, 2001.

Beggs, P. J. and Walczyk, N. E.: Impacts of climate change on plant food allergencs; a previously unrecognized threat to human health, Air Qual. Atmos. Health, 1, 119-123, 2008.

Brown, C. M., Anderson, H. A., and Etzel, R. A.: Asthma. The states' challenge, Public Health Rep., 112, 198-205, 1997.

Burney, P.: The changing prevalence of asthma? Thorax, 57, Suppl. 2, II36-II39, 2002.

California/EPA: Children's Environmental Heath Program, Biennial Report (2004-2005), http://www.arb.ca.gov/research/apr/ past/94-331a.pdf, last access: 27 February 2012, 2006.

Centers for Disease Control and Prevention: CDC Surveillance Summaries, MMWR 1998, 47(No SS-1): www.cdc.gov/mmwr/ preview/mmwrhtml/00052262.htm, 24 April, 1998.

Centers for Disease Control and Prevention, National Center for Health Statistics: National Health Interview Survey, 2001-2010, http://www.cdc.gov/asthma/nhis/default.htm, last access: 28 February 2012.

Centers for Disease Control and Prevention, National Center for Health Statistics: Summary Health Statistics for U.S. Children: National Health Interview Survey 2008, Hyattsville, Maryland, DHHS Publication No (PHS) 2010-1572, December 2009.

Centers for Disease Control and Prevention, National Health Statistics Reports, National Asthma Control Program: Asthma Fast Facts: A Summary of Important Statistics: http: //www.cdc.gov/asthma/pdfs/asthma_fast_facts_statistics.pdf, last access: 27 February 2012, 2011.

Committee TISoAaAiCIS: Worldwide variation in prevalence of symptoms of asthma, allergic rhinoconjuntivities and atopic eczema, ISAAC, Lancet 351, 1225-1232, 1998.

Cowherd, Ch. and Kuykendal, W.: Paper No. WP96.04, Proceedings of the Annual Meeting of the Air and Waste Management 
Association, June, 1996.

Countess, R.: Reconciling fugitive dust emissions inventories with ambient measurements, 12th Annual EPA EI Mtg., San Diego, CA, 29 April-1 May, 2003.

Delfino, R. J., Zeiger, R. S., Seltzer, J. M., Street, D. H., and McLaren, Ch. E.: Association of asthma symptoms with peak particulate air pollution and effect modification by antiinflammatory medication use, Environ. Health Persp., 111, 607617, 2002.

Dolk, H. and Vrijheid, M.: The impact of environmental pollution on congenital anomalies, British Med. Bulletin, 68, 25-45, 2003.

Fernando, H. J. S., Mammarella, M. C., Grandoni, G., Fedele, P., Di Marco, R., Dimitrova, R., and Hyde, P.: Forecasting PM $_{10}$ in Metropolitan Areas: Efficacy of Neural Networks, Environ. Pollut., 163, 62-67, 2011.

Jacobs, J., Kreutzer, R., and Smith, D.: Rice Burning and Asthma Hospitalizations, Butte County, California, 1983-1992, Environ. Health Persp., 105, 980-985, 1997.

Janson, C., Chinn, S., Jarvis, D., and Burney, P.: Physician diagnosed asthma and drug utilization in the European Community Health Survey, Eur Respir J., 10, 1795-1802, 1997.

Hansen, C., Neller, A., Williams, G., and Simpson, R.: Material exposure to low levels of ambient air pollution and preterm birth in Brisbane, Australia, BJOG, 113, 935-941, 2006.

Holgate, S. T.: The epidemic of allergy and asthma, Nature, 402(6760 Suppl.), B2-B4, 1999.

Hosmer, D. and Lemeshow. S.: Applied Logistic Regression, John Wiley \& Sons, Inc., 2000.

Levy, D., Lumley, T., Sheppard, L., and Checkoway, H.: Referent selection in case-crossover analyses of acute health effects of air pollution, Epidemiology, 12, 186-192, 2001

Lin, M., Steib, D., and Chen, Y.: Coarse particulate matter and hospitalization for respiratory infections in children younger than 15 years in Toronto: a case-crossover analysis, Pediatrics, 116, 235-240, 2005.

Lipsett, M., Hurley, S., and Ostro, B.: Air pollution and emergency room visits for asthma in Santa Clara county, California, Envir. Health Persp., 105, 216-222, doi:10.1289/ehp.97105216, 1997.

Lumley, T. and Levy, D.: Bias in the case-crossover design: implications for studies of air pollution, Environmetrics, 11, 689-704, 2000.

Maciejczyk, P. B., Offenberg, J. H., Clemente, J., Blaustein, M., Thurston, G. D., and Chi Chen, L.: Ambient pollutant concentrations measured by a mobile laboratory in South Bronx, NY, Atmos. Environ., 38, 5283-5294, 2004.

Maclure, M.: The case-crossover design: a method for studying transient effects on the risk of acute events, Am. J. Epidemiol., 133, 144-153, 1991.

Magnus, P. and Jaakkola, J. J. K.: Secular trend in the occurrence of asthma among children and adults: critical appraisal of repeated cross sectional surveys, BMJ, 314, 1795-1799, 1997.

Mannino, D., Homa, D., Pertowski, C., Ashizawa, A., Nixon, L., Johnson, C., Ball, L., Jack, E., and Kang, D.: Surveillance for asthma-United States, 1960-1995. In: Survellance Summaries, MMWR, 47(No. SS-5), 1-27, 24 April, 1998.

Mannino, D., Homa, D., Akinbami, L., Moorman, J., Gwynn, C., and Redd, S.: Surveillance for asthma-United States, 19801999. In: Surveillance Summaries, MMWR, 51(No. SS-1), 113, 29 March, 2002.
Mammarella, M. C., Grandoni, G., Fedele, P., Di Marco, R. A., Fernando, H. J. S., Dimitrova, R., and Hyde, P.: EnviNNet: a Neural Network for hindcasting $\mathrm{PM}_{10}$ in Urban Phoenix, AMS 89th Annual Meeting /Eighth Symposium on the Urban Environment, 10-15 January, Phoenix, 2009.

Medina-Ramon, M., Zanobetti, A. and Schwartz, J.: The effect of ozone and $\mathrm{PM}_{10}$ on hospital admissions for pneumonia and chronic obstructive pulmonary disease: a national multicity study, Am. J. Epidemiol., 163, 579-588, 2006.

Midwest Research Institute (MRI): Analysis of the fine fraction of particulate matter in fugitive dust, Final Report for Western Governors' Association Western Regional Air Partnership (WRAP), MPI Project No. 110397, October, 2005.

Midwest Research Institute (MRI): Background document for revisions to fine fraction ratious used for AP-42 fugitive dust emission factors, for Western Governors' Association Western Regional Air Partnership (WRAP), MPI Project No. 110397, November, 2006.

Monteil, M.: Saharan dust clouds and human health in the Englishspeaking Caribbean: what we know and don't know, Environ. Geochem Health, 30, 339-343, doi:10.1007/s10653-008-91620,2008 .

Nauenberg, E. and Basu, K.: Effect of insurance coverage on the relationship between asthma hospitalizations and exposure to air pollution, Public Health Rep. March-April, 114, 135-148, 1999.

Neas, L., Schwartz, J., and Dockery, D.: A case-crossover analysis of air pollution and mortality in Philadelphia, Environ. Health Persp., 107, 629-631, 1999.

Norris, G., Young-Pong, Sh. N., Koenig, J. Q., Larson, T. V., Sheppard, L., and Stout, J. W.: An association between fine particles and asthma emergency department visits for children in Seattle, Environ. Health Persp., 107, 489-493, 1999.

Ono, D.: Ambient $\mathrm{PM}_{2.5} / \mathrm{PM}_{10}$ ratios for dust events from the Keeler dunes, Great Baron UAPCD, Bishop, CA, 2005.

Pace, T. G.: Examination of multiplier used to estimate $\mathrm{PM}_{2.5}$ fugitive dust emissions from $\mathrm{PM}_{10}$, Presented at the EPA Emission Inventory Conference, Las Vegas NV, April, 2005.

Peel, J., Tolbert, P., Klein, M., Metzger, K., Flanders, W., Todd, K., Mulholland, J., Ryan, P., and Frumkin, H.: Ambient air pollution and respiratory emergency department visits, Epidemiology, 16, 164-174, 2005.

Peters, A., Dockery, D. W., Heinrich, J., and Wichmann, H. E.: Short-term effects of particulate air pollution on respiratory morbidity in asthmatic children, Eur. Respir. J., 10, 872-879, ISSN 0903-1936, 1997.

Redelmeier, D. and Tibishirani. R.: Association between cellulartelephone calls and motor vehicle collisions, The New England Journal of Medicine, 336, 453-458, 1997.

Scapellato, M. L., Canova, C., de Simone, A., Carrieri, M., Maestrelli, P., Simonato, L., and Bartolucci, G.B.: Personal $\mathrm{PM}_{10}$ exposure in asthmatic adults in Padova, Italy: seasonal variability and factors affecting individual concentrations of particulate matter, Int. J. Hyg. Environ. Health, 212, 626-636, 2009.

Schwartz, J. and Dockery, D. W.: Increased mortality in Philadelphia associated with daily air pollution concentrations, Am. Rev. Respir. Dis., 145, 600-604, 1992.

Schwartz, J., Slater, D., Larson, T. V., Pierson, W. E., and Koenig, J. Q.: Particulate air pollution and hospital emergency room visits for asthma in Seattle, Am. Rev. Respir. Dis., 147, 826-31, 1993. 
Steenland, K. and Deddens, J. A.: A practical guide to exposureresponse analyses and risk assessment in occupational epidemiology, Epidemiology, 15, 63-70, 2004.

Tolbert, P. E., Mulholland, J. A., MacIntosh, D. L., Xu, F., Daniels, D., Devine, O. J., Carlin, B. P., Klein, M., Dorley, J., Butler, A. J., Nordenberg, D. F., Frumkin, H., Ryan, P. B., and White, M. C.: Air quality and pediatric emergency room visits for asthma in Atlanta, Georgia, USA, Am. J. Epidemiol., 151, 798-810, 2000.

Viana, M., Querol, X., Alastuey, A., Ballester, F., Llopp, S., Espluguues, A., Fernandez-Patier, R., Garcia Dos Santos, S., and Herce, M. D.: Characterizing exposure to PM aerosols for an epidemiological study, Atmos. Environ., 42, 1552-1568, 2008.

Vollmer, W. M., Osborn, M. L., and Buist, A. S.: 20-year trends in prevalence of asthma and chronic airflow obstruction in an HMO, Am. J. Respir. Crit. Care Med., 157, 1079-1084, 1998.
World Health Organization, regional Office for Europe: Health aspects of air pollution with particulate matter, ozone and nitrogen dioxide, Report 2003, Bonn, Germany, 2003.

World Health Organization, regional Office for Europe: Global surveillance, prevention and control of chronic respiratory diseases, Report 2007, Geneva, Switzerland, ISBN 978924156346 8, 2007.

US Environmental Protection Agency (EPA): Air quality criteria for particulate matter (Final Report, Oct 2004), Washington, DC, EPA 600/P-99/002aF-bF, 2004.

Yeatts, K., Hanna, A., Zhu, Zh., Xiu, A., Arora, G., Meng, Q., Pinto, J., and Robison, P.: Ozone, $\mathrm{PM}_{10}$, and synoptic circulation patterns associated with asthma/myocardial infarction hospital admissions, Epidemiology, 20, S226, doi:10.1097/01.ede.0000362758.69045.9a, 2009. 